\title{
Constructing Commongrounds: Everyday Lifeworlds Beyond Politicized Ethnicities in Sri Lanka by Anton Piyarathne (Colombo: Sarasavi Publishers, 2018), Rs.750/-.
}

\author{
Reviewed by Kalinga Tudor Silva* \\ Emeritus Professor in Sociology, University of Peradeniya, Peradeniya, Sri Lanka.
}

Since anti-Tamil riots in 1983, the social science literature on Sri Lanka has been preoccupied with understanding the causes and consequences of ethnic polarization in the country, including the emergence of rival Sinhala, Tamil and Islamic nationalisms, politics of conflict and confrontation including the war itself as well as an intractable wave of street violence seemingly triggered by ethnic sentiments, grievances and hostilities. In contrast, Constructing Commongrounds by Anton Piyarathne moves in the opposite direction- it seeks to identify the commongrounds that enable people of diverse ethnicities living side by side to interact with each other and establish peaceful relations in their day-to-day life in spite of the firmly established identity politics that invariably divide "us" and "them" and limit people to a tunnel vision which diverts attention away from human unity and common problems of poverty, landlessness, unemployment and environmental challenges affecting all groups to varying degrees.

The book implies that the social scientists have so far paid too much attention on politically driven nationalist agendas and the corresponding processes of emotionally charged "divide and rule" campaigns to the relative neglect of community driven desires for unity, coexistence and search for commongrounds, processes that can actually show us the way out of the current impasse and volcanic eruptions in political nerve centres as well as market places, facebook and on many other fronts. This publication can be seen as a welcome addition to the social science literature on Sri Lanka by a younger scholar deeply concerned about the social and political reality in the country and the perceived powerlessness of social sciences to influence the very processes carefully scrutinized, assessed and documented by them.

\section{ETHNICITY AND COMMONGROUNDS}

"Ethnicity" and "commongrounds" are the central themes and part and parcel of the connecting thread of this book. The author, however, tends to avoid a rigorous definition of these terms or use them in a consistent manner throughout the text.

In the introduction to the book Piyarathne states that, "This book is as much about ethnicity as it is about all that does not fit the common usage of the term" (Piyarathne, 2018: p. 16). He deploys definitions of ethnicity given by several other authors as follows.

"Ethnicity is about use of cultural traits in social boundary making" (Barth, 1969).

"Ethnicity is a product of contact and not of isolation" (Eriksen, 2010).

"Ethnicity implies the subjective, symbolic or emblematic use by a group of people of any aspect of culture" (Georg de Vos, 1975).

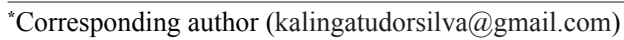

This article is published under the Creative Commons CC-BY-ND License (http://creativecommons.org/licenses/ by-nd/4.0/).This license permits use, distribution and reproduction, commercial and non-commercial, provided that the original work is properly cited and is not changed anyway. 
"Ethnicity is a manifestation of what our and their culture is about" (Ingold, 2011).

"Ethnic differences are better conceptualized as muted or broken resemblances" (Harrison, 2002).

As all these definitions imply, the book counters a primordialist interpretation of ethnicity and efforts to essentialize ethnicity as the only or even the most important aspect of a person's identity.

What comes closest to a definition of commongrounds is formulated in the book in following terms.

"I understand commongrounds as inhabitants' continuous and creative efforts to live and relate to each other in fields of common endeavour informed by embodied (conscious or unconscious) understanding of the social and material world. To put it slightly differently, commongrounds involve shared positions and abilities to use cultural resources in distinctive, pragmatic and creative ways that best match emerging situations and contingencies, while taking account of external forces/limits that threaten local social living in its meeting of external needs" (Piyarathne, 2018: p. 7).

On the whole, commongrounds seek to understand not so much of what divides up people in the form of ethnic divisions but what connects them in the midst of intense political pressures to the contrary.

"My aim in this book is to make hitherto invisible commongrounds visible. I submit that Sri Lanka has a politically crafted ethnic "problem", which... admits solution and is not a "mystery" that will never be solved" (ibid. p. 6-7).

This, in turn, implies that an ethnic animus that demonizes the ethnic other is part of the problem to be explained rather than an explanation by itself, as implied in a large body of anthropology of violence literature on Sri Lanka.

\section{STUDY SITES FROM COLOMBO TO EAST COAST}

The book is based on ethnographic field research in four different sites strategically selected for the purpose of identifying commongrounds connecting people of different ethnicities. The first two sites, Crow Island and De Mel Watta, are located in the outskirts of the city of Colombo and the next two sites, Panama and Pottuvil, are located in the southern periphery of east coast of Sri Lanka. Both the middle-class community of
Crow Island and the shantytown of De Mel Watta are multiethnic communities with multiple commongrounds such as interethnic marriages, religious pluralism and multiple forms of mutual help and social interaction. In these contrasting urban sites located at different positions in the class continuum, the researcher found that the social class understood in terms of Bourdieu's notion of habitus and social capital, provides commongrounds countering the overarching influence of ethnicity and the resulting processes of political polarization and violence.

Panama is a site of commongrounds because Tamil and Sinhala speakers have intermarried across the ethnic divide largely along caste lines. Here instead of class dynamics of social and cultural capital formation outside of ethnicity, caste becomes part of the commongrounds both inside and outside of the ethnic model. The author, however, does not acknowledge or explore caste as a basis of commongrounds perhaps due to ideological reasons, in my view, limiting his understanding of the dynamic play between social inequality and ethnicity. Complicating the picture further, the Pottuvil site enables the author to bring in Muslim economics and politics into the discussion of commongrounds in a background of three-way exchanges among Muslims (traders), Tamils and Sinhalas (farmers and service providers based on the caste model perhaps increasingly giving way to a sense of social injustice largely conceptualized in ethnic terms).

\section{OVERALL ASSESSMENT}

This is certainly an important contribution to Sri Lankan studies not only because it provides a new perspective towards understanding the intractable problem of ethnic mobilization in modern Sri Lanka, but also because it tries to find a way out of the current impasse resulting from essentializing ethnicity, pathologizing the ethnic turn in Sri Lankan society and culture and uncritical adoption of externally derived formulas and remedies. What the author identifies as commongrounds, however loosely defined such commongrounds are, should form an important basis of a multitrack approach to promote mutual trust among communities and overcome identity politics fueling hostilities, ethnic hatred and inherent attribution of one's own failures to the evil actions of an "ethnic other". The book has a powerful message to the political elite as well as students of Sri Lankan politics and society. Commongrounds may be seen as a welcome effort to debunk ethnicity as the sole determinant of social, economic and psychosocial dynamics within a global order producing mass movements, transcultural processes, new forms of inequalities and related insecurities and vulnerabilities. 
The book is well written, cogently argued and logically presented. Being an outcome of the author's $\mathrm{PhD}$ research, the book builds on a vast body of global literature on ethnicity and identity politics and much of the relevant literature on Sri Lanka. From the angle of everyday ethnicity in Sri Lanka, two important omissions are T. Gaasbeek's $\mathrm{PhD}$ thesis on Bridging Troubled Waters: Everyday Interethnic Interaction in the Context of Violent Conflict in Kottiyar Pattu, Trincomalee, Sri Lanka" (2010) and Checkpoint, Temple, Church and Mosque: A Collaborative Ethnography of War and Peace by Spencer et al. (2015). Readability of Constructing Commongrounds would have improved if there were more illustrations, pictures and an index at the end of the book.

The author clearly has some unique strengths in undertaking the study at hand. For instance, he seems to have trilingual skills enabling him to work in a predominantly English speaking middle class community in Colombo, ethnically-mixed communities in Crow Island, De Mel Watta and in Panama and predominantly Tamil speaking Pottuvil community. However, as an ethnographic account of four communities, the study has some serious flaws. None of the communities studied are described in sufficient ethnographic detail. For instance, there is no detailed demographic profile of any of these communities. While concepts such as majority and minority are used in respect of different communities, the population breakdown by ethnicity is not given in respect of any of the study locations. The author need not do a detailed population census in each of the four study locations as typically the case in conventional ethnographic studies, but this may have been easily established through available secondary data such as Grama Niladhari records. Similarly, the livelihoods in each of these communities are touched in most rudimentary ways even when material living conditions are discussed, particularly when referring to phenomena such as social class. No community maps are presented even when discussing beach as a commonground in Crow Island. One can understand the difficulty of providing such details in respect of four study locations which are $400 \mathrm{kms}$ away from each other in some cases, but this cannot be given as an excuse for not doing a thorough ethnography. At best, the study methodology used can be described as a rapid ethnography minus thorough ethnographic details. The author uses pseudonyms to identify individual informants but the actual names of the communities and places are used throughout the text perhaps making it possible to trace the individuals even when people of the underworld are mentioned in respect of De Mel Watta. These are some sensitive ethical issues that requires closer scrutiny, particularly when it comes to challenges of what the author describes as native ethnography. Nonetheless, the study also makes a useful methodological contribution about "doing anthropology at home". The use of endearing terms such as "Gopalan anna" and "Rinosa akka" to describe key informants as well as the use of Sinhala and Tamil terms have added a distinct Lankan flavour to the ethnographic account.

Unlike many other studies in the local social science scene, this study is well informed by theory. In conceptualizing ethnicity and commongrounds, the author draws heavily from a galaxy of theorists, including Pierre Bourdieu, Michael Jackson and Simon Harrison. Bourdieu's notion of social, cultural and symbolic capital as well as the notion of habitus are deployed effectively in "constructing commongrounds" as a corrective to an essentialized notion of ethnicity. There is, however, a tendency to overtheorize particularly in the introductory chapter making it too dense and with little relevance to the analysis in the subsequent chapters. The idea of commongrounds is used too often to refer to vastly different things with no clear analytical focus or no analytical rigour as such. To illustrate this I can give several examples from the book.

"Commongrounds are not settled states but continuing fields of interactive struggle" (Piyarathne, 2018: p. 6).

"Commongrounds are not always peaceful but tense, lived out in ups and downs and shifting" (ibid. p. 8).

"In a bid to understand commongrounds, I analyzed relationships among members of society via their social networks of informants (ibid. p. 17).

"The beach is a commonground for people: men, women, young, old, lovers. Married, divorced, Buddhists, Hindus. Christians, Muslims ....." (ibid. p. 80).

"Post boat trip 'drinks' too generated common grounds..." (ibid. p. 97).

Thus, the idea of commongrounds is used to identify a physical space used by people (e.g. beach), to refer to social relations, to characterize shared drinks during a picnic and so many different aspects of life in various communities studied. Some of the analytical content of the original definition of commongrounds stated earlier such as use of cultural resources to unify people, do not figure in examples such as the use of the beach.

This rather loose use of the concept of commongrounds also does not enable the author to make an analytic 
break where necessary. For instance, in analyzing the phenomenon of "greese bhutam" in Pottuvil, one of the few instances when the researcher turns to a discussion of ethnic hostilities in one of his study sites, the author finds the manipulation of cultural symbols (e.g. blood, purity of women) for articulating fears and suspicion of one ethnic group against another. Is this, indeed, a negative manipulation of commongrounds for violence and conflict? If not, what are the distinctive features that separate ethnic border crossing aspects of commongrounds from similar social processes producing conflict and tension? These are some issues that require closer scrutiny from the angle of understanding dialectical social processes that produce class or caste solidarity as against ethnic tension.

These problems aside, this is an important scholarly work that should inspire and influence further research on ethnicity and identity politics in Sri Lanka. The author should be congratulated for producing a potentially path breaking study that should indeed encourage us to explore the social realities and lived experiences beyond the messy world of politicized ethnicities and ethnicized politics. 